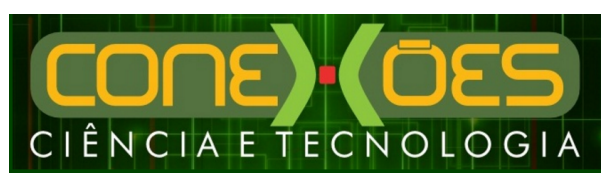

\title{
TURISMO RELIGIOSO: UM ESTUDO SOBRE A DEMANDA DE UM ROTEIRO TURÍSTICO DAS IGREJAS CATÓLICAS DO CENTRO DE FORTALEZA - CEARÁ - BRASIL
}

\author{
Gilberg Serpa dos Anjos e Anna Erika Ferreira Lima \\ Instituto Federal de Educação, Ciência e Tecnologia do Ceará \\ Campus de Fortaleza \\ <gilbergad@gmail.com><annaerika@ifce.edu.br>
}

DOI: 10.21439/conexoes.v11i5.1270

\begin{abstract}
Resumo. O objetivo do presente artigo foi analisar a viabilidade de um Roteiro Turístico voltado para o segmento religioso no centro de Fortaleza. O Ceará é um destino turístico consolidado no Brasil, e o desenvolvimento de um roteiro como esse poderia surgir como uma alternativa de turismo cultural. Como base metodológica esta pesquisa teve o estudo de caso e como métodos de execução contou com a pesquisa bibliográfica, a documental e a pesquisa de campo, onde foram aplicados 45 questionários junto à turistas durante os meses de janeiro e fevereiro de 2017, além de diário de campo, onde foram feitas anotações referentes à falas dos turistas entrevistados. Esses instrumentais tiveram importância fundamental para analisar a possibilidade da implantação de um roteiro cultural e religioso referente às igrejas católicas do Centro da Capital Cearense. Como resultado foi elaborado um mapa do supracitado roteiro, bem como efetivado o levantamento geo-histórico de tais atrativos religiosos culturais.
\end{abstract}

Palavras-chaves: Turismo Cultural. Turismo Religioso. Igrejas Católicas. Centro Histórico de Fortaleza.

\begin{abstract}
The objective of this article was to analyze the viability of a Tourism Roadmap for the religious segment in the center of Fortaleza. Ceará is one of the main tourism destinations in Brazil, and the development of route like that could emerge as an alternative of cultural tourism. As a methodological basis, this research had the case study and as methods of execution counted on the bibliographical research, the documentary and the field research, where 45 questionnaires were applied to the tourists during the months of January and February of 2017, as well as daily field, where annotations were made regarding the speeches of the tourists interviewed. These instruments were fundamentally important to analyze the possibility of establishing a cultural and religious itinerary referring to the Catholic churches of the Center of the Ceará's capital. As a result, a map of the aforementioned itinerary was drawn up, as well as a geo-historical survey of such cultural religious attractions.
\end{abstract}

Keywords: Cultural Tourism. Religious Tourism. Catholic Churches. Historic Center of Fortaleza.

\section{PROBLEMATIZAÇÃo}

O Turismo Religioso é um segmento de mercado crescente dentro da atividade turística, e que movimenta milhares de pessoas que por motivações diferentes, buscam conhecer atrativos e destinos que são considerados sagrados. De acordo com o Ministério do Turismo, em 2014 mais de dezessete milhões de brasileiros realizaram viagens que se classificam como parte do segmento religioso. Segundo pesquisa realizada pelo Datafolha
(2013), no Brasil o catolicismo, sob o qual versará a análise da presente pesquisa, mobiliza $57 \%$ da população - aproximadamente 116 milhões de pessoas -, enquanto as igrejas evangélicas arregimentam perto de 42 milhões de fiéis (25\%). Os espíritas, com 3\%, estão em terceiro lugar, seguidos por testemunhas de Jeová, umbandistas, budistas, adeptos do candomblé, judeus e muçulmanos.

Conforme informações da Edição no 39 da Revista 
Comércio \& Serviços (2015), esse público estimula a realização de eventos no País e movimenta a economia com a construção de templos e igrejas; instalação de sistemas de segurança; vendas de artigos religiosos e shows. Festas e romarias estimulam o Turismo Religioso, com a movimentação de aproximadamente $\mathrm{R} \$ 15$ bilhões, segundo o Instituto Data Popular.

Conforme o Serviço de Evangelização da América Latina, o qual elaborou um Censo do setor no período de 2013/2014, este concluiu a existência de 350 santuários e 11.312 paróquias no País, sendo que os templos evangélicos somam mais de 220 mil. O Turismo Religioso tem se ramificado e fortalecido neste nicho de mercado, uma vez que se têm informações que,

Os destinos mais procurados pelos católicos são o Santuário Nacional de Aparecida (São Paulo), com 10 a 12 milhões de visitantes ao longo do ano; Círio de Nazaré (Belém); Juazeiro do Norte (Ceará), para a romaria do $\mathrm{Pa}$ dre Cícero; e Nova Trento (Santa Catarina), local do Santuário de Madre Paulina, a primeira santa brasileira. São municípios cuja principal fonte de arrecadação é o turismo religioso. Os evangélicos neopentecostais, por sua vez, têm, desde o ano passado, um exuberante cartão-postal: o Templo de Salomão, da Igreja Universal do Reino de Deus, cujas dimensões superam as de um campo de futebol e tem 100 mil metros quadrados de área construída. O empreendimento recebe $10 \mathrm{mil}$ pessoas sentadas e custou $\mathrm{R} \$ 680$ milhões à Universal, sendo ricamente decorado com cadeiras importadas da Espanha e esteira rolante para os dízimos (FECOMERCIO, 2015. p.24).

As Igrejas católicas, além de templos sagrados, são obras arquitetônicas, históricas e culturais, as quais se tornam importantes atrativos turísticos de uma região, somados ao fator que compõe a paisagem urbana que por si própria, é considerada um atrativo. A religião como manifestação cultural se trata de uma das características mais marcantes de um povo. Para Andrade (2000), sobre tal fenômeno, explica que "o conjunto de atividades, com utilização parcial ou total de equipamentos, e a realização de visitas a receptivos que expressam sentimentos místicos ou suscitam a fé, a esperança e a caridade aos crentes ou pessoas vinculadas a religiões, denomina-se turismo religioso" (p.77).

Alternativas de turismo vêm se tornando essenciais nos últimos tempos, visto que o perfil do turista se torna cada vez mais exigente. Ferreira, Aguiar e Pinto (2012) menciona que a globalização normalizou a vida cultural das cidades, em eventos, exposições e tendências que se assemelham e em territórios cada vez mais idênticos. Essa mudança também se deve à facilidade que o mesmo tem na hora de escolher um destino. Devido a esse fator, se faz necessária a preservação e criação de uma identidade cultural que seja única, e que possa diferenciar um destino de outro.

Tendo em vista a quantidade expressiva de igrejas no Centro da cidade de Fortaleza, as quais somam um quantitativo de oito, a pesquisa se delineou com o objetivo principal de identificar e analisar a viabilidade de um roteiro turístico formado pelas igrejas católicas localizadas no centro da Capital Cearense. O estudo teve como objetivos específicos descrever as igrejas que compõe o centro histórico de Fortaleza, ressaltando os fatores históricos e culturais que marcaram suas existências; e identificar a demanda de um roteiro turístico voltado para o segmento religioso, através dos turistas que visitam o centro histórico.

Para tanto objetivou-se, a partir de uma amostra aleatória, aplicar 45 questionários semi-estruturados (APÊNDICE A) junto a turistas que se encontravam visitando a cidade de Fortaleza, no período de 02 de janeiro à 02 de fevereiro de 2017. A pesquisa se delineou sob o viés qualitativo, onde foram analisadas as respostas e efetivadas as análises e interpretações das mesmas.

Nesse cenário buscou-se responder a questão: Qual seria a viabilidade da elaboração e implementação de um roteiro religioso das igrejas católicas no Centro da cidade de Fortaleza - Ceará - Brasil?

No Brasil existe uma quantidade expressiva de destinações religiosa, onde se esboçam manifestações de fé como: na Passarela da Fé em Aparecida (SP), na Corda do Círio em Belém (PA) ou no Templo de Tia Neiva (DF) ou até mesmo nas cidades de Nova Trento (SC), Bom Jesus da Lapa (BA), Canindé ou Juazeiro do Norte (CE) como indica Oliveira (2008). Essas destinações religiosas fazem movimentar cerca de $15 \mathrm{mi}-$ lhões de pessoas que se deslocam anualmente no país por motivos religiosos, movimentando, no mínimo, $\mathrm{R} \$$ 6 bilhões por ano (EMBRATUR, 2015).

Foi a partir desta constatação que o Ministério do Esporte e Turismo, através da Instituto Brasileiro de Turismo (EMBRATUR), decidiu investir nesse segmento. "Estamos transformando esta matéria prima em produto. A ideia é utilizar a estrutura existente, estimulando a profissionalização e a qualificação turística para melhor aproveitar este nicho que movimenta, no mínimo, R\$ 6 bilhões por ano" (op.cit.). Em seu artigo 
intitulado "Fé faz o Brasil se Multiplicar", a jornalista Gouthier (2000) indica que "toda essa movimentação religiosa é um dos traços mais fortes da cultura do Brasil" ao citar Frei Chico.

Entretanto, faz-se essencial afirmar conforme Oliveira (2008), que o Turismo Religioso não é prioritariamente ou necessariamente, um turismo praticado por religiosos, místicos, santos populares, devotos e sacerdotes/profissionais de qualquer credo ou confissão religiosa. O adjetivo "religioso" deve ser reconhecido em sua amplitude espiritual e metafísica, embora seja preciso observar criticamente a sua aproximação com a perspectiva cristã. Portanto, a correta definição para esse tipo de turismo encontra-se num exercício aproximativo. Trata-se de um fazer turístico capaz de manifestar algum dado de religiosidade. E é exatamente na religiosidade - no ato popular de professar o sistema de crenças chamado de Religião - que o Turismo Religioso pode ser comparado às peregrinações e romarias aos lugares sagrados, visitações a locais que despertem o imaginário religioso ou no próprio locus da fé e da expressão da religião em momentos também sagrados como é o caso das igrejas.

É sobre esse olhar crítico e analítico, que se construiu o presente artigo, o qual está dividido em quatro tópicos, onde no Tópico dois se discute a perspectiva conceitual do Turismo Cultural e do Turismo Religioso; o Tópico três se pauta no Turismo Religioso no Brasil e no Ceará e no Tópico quatro se coloca a proposta de Turismo Religioso ligado às igrejas do Centro da Cidade de Fortaleza, as quais são consideradas como patrimônios materiais da/na sociedade cearense.

\section{UMA COMPREENSÃO CONCEITUAL DO TURISMO CULTURAL E RELIGIOSO: UMA PROPOSTA DE ROTEIRO}

Enquanto fenômeno social, o turismo somente ocorre mediante deslocamento de pessoas voluntário e temporário com interesses diversos (TORRE, 1992).

A compreensão de Torre (1992) indica de forma ampla como seria a atividade turística, onde observa-se a importância do deslocamento como sendo algo que acontece por interesse natural de pessoas por conhecer novos lugares, mas principalmente por um espaço de tempo definido, ou seja, que eventualmente ocorra o retorno dessas pessoas ao seu local de origem. Esse interesse surge pela busca de conhecimento sobre um novo local, onde tais sujeitos objetivam conhecer atrativos naturais, históricos, culturais, religiosos, dentre outros. Mesmo a cultura sendo o fator secundário na escolha por um lugar de destino, qualquer viagem (lazer, férias, negócios) envolve elementos culturais e, portanto, "pela sua própria natureza, a arte de viajar retira os turistas da sua cultura matriz e coloca-os temporariamente num meio cultural diferente (MCKERCHER; CROS, 2002, p.1).

Logo, a prática do turismo cultural abrange todos os aspectos da cultura específica de um país, de uma região ou de uma comunidade (RAJ 2004) e, ainda, as atividades associadas à cultura do dia-a-dia do local (SMITH ). Pode-se ir além, reitera-se aqui que independe da religião, o ato de conhecer monumentos, santuários; ou efetivar caminhadas, independe dos sujeitos serem religiosos. Muitos tomam tais experiências como um desejo de conhecer uma nova cultura, submergindo em um universo comum a outro grupo social. Na realidade, o Turismo Cultural, de acordo com ??) "constitui uma manifestação do consumo e cultura de massas" (p.87), sendo necessário analisá-lo sobre um viés interdisciplinar.

\subsection{A Interface entre o Turismo Cultural e o Tu- rismo Religioso.}

A atividade turística é interdisciplinar, pois através dela, vários aspectos se entrelaçam, sendo eles não somente relacionados a economia, como também a cultura e aspectos sociais
O Turismo, além de um importante instru- mento de promoção social e de dinamização econômica, é também e, principalmente, uma atividade cultural. Conhecer lugares, assistir apresentações de manifestações artísticas, de- gustar pratos peculiares de cada região, com- partilhar com nativos a experiência de uma feira local, é conhecer elementos que dizem respeito a pessoas e suas sensibilidades, suas normas e valores, suas emoções. É um exer- cício de se colocar por alguns momentos na condição do outro que experimenta cotidia- namente aquilo que, aos turistas, é proporcio- nado fortuitamente (MARTINS, 2003, p.49).

Neste caso, quando o turista se desloca, mesmo que seja para um destino, como uma praia, que pode não possuir patrimônios materiais como igrejas e edifícios antigos, este se depara com sotaques, culinária, costumes, crenças, dentre outros aspectos culturais que vão de encontro ao seu habitual.

De acordo com o Ministério do Turismo (2006), Turismo Cultural compreende as atividades turísticas relacionadas à vivência do conjunto de elementos significativos do patrimônio histórico e cultural e dos eventos 
TURISMO RELIGIOSO: UM ESTUDO SOBRE A DEMANDA DE UM ROTEIRO TURÍSTICO DAS IGREJAS CATÓLICAS DO CENTRO DE FORTALEZA - CEARÁ - BRASIL

culturais, valorizando e promovendo os bens materiais e imateriais da cultura. Dessa forma, podemos identificar vários tipos de turismo que se caracterizem como turismo cultural, seja ele de característica arqueológica, religiosa, gastronômica, dentre outras.

A caracterização de um tipo de turismo parte diretamente da motivação que impulsionou o turismo em primeiro lugar. Dentre os seguimentos do Turismo Cultural, o Turismo Religioso se enquadraria nesse cenário, uma vez que a definição de cultura abrange todas as formas de expressão do homem, e a religião e todas as formas de manifestação de fé são características presentes no ser humano há séculos. Além de fazer parte da história, a religião é um fator influenciador em diversas formas na cultura de um povo.

A religião está presente de maneiras diversas na cultura supostamente secular da qual provenho. As imagens e conceitos religiosos ou teológicos presentes na literatura, no cinema e na televisão nos lembram de que a religião pode ser concebida como uma consciência particular que levamos conosco em nosso encontro com a arte ou encontramos expressa na arte. A religião também se manifesta como atividade ritualizada que expressa valores e compromissos profundos. Precisamos ver os paralelos a rituais religiosos em eventos como a final do campeonato americano de futebol ou o concurso de beleza para escolher a Miss Estados Unidos. (MAHAN, 1998, p.193).

Sendo assim, pode-se identificar que, qualquer pessoa que se desloque para um destino a fim de conhecer, vivenciar ou participar de atrativos e eventos relacionados a religião são considerados turistas do segmento religioso.

Quando se discute o Turismo Religioso encontramse dois tipos de classificação mais comuns que se sobressaem na prática desta atividade turística. Fala-se de "peregrino" ou "turista peregrino" e o designado "turista religioso" (SOUSA; PINHEIRO, 2014). No Brasil é comum uma tipologia chamada de "romeiro", o qual semelhante ao Peregrino não se identificam como turista religioso, pois visitam o lugar sagrado somente com o intuito de renovação espiritual. Conforme Terrin (2004), esse tipo de turista, evidentemente que tais posições apresentam controvérsias que serão discutidas na sequência; geralmente se hospeda e utiliza meios de transportes e de restauração precários, sendo como uma forma de ser perdoado de seus pecados e iniciar um novo ciclo em sua vida espiritual.
Oliveira (2008, p.67) classifica o romeiro como "o membro da comunidade que faz a jornada religiosa comum", constituindo uma viagem de caráter coletivo, como aqueles que se dirigem à Juazeiro do Norte durante a Romaria do Padre Cícero nos meses de Julho, quando ocorre a Romaria da Morte do Padre; no mês de setembro, quando corre a Romaria de Nossa Senhora das Dores e em Novembro na Romaria de Finados (Figura 1). Para a Secretaria de Romaria, de Juazeiro do Norte, a que mais agrega romeiros é a Romaria de Finados, quando se chega a receber 450 mil romeiros, sendo que a cidade recebe até dois milhões e quinhentas mil pessoas ao ano.

Figura 1: Quantitativo de romeiros por Romarias em Juazeiro do Norte - Ceará.

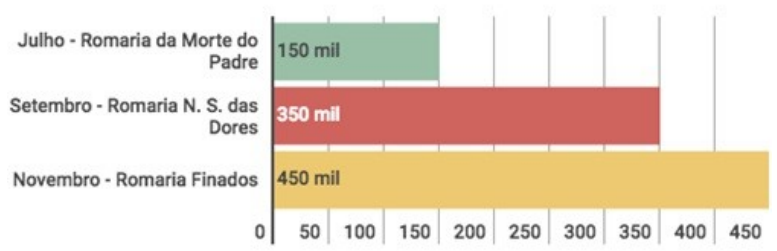

Fonte:Secretaria de Turismo e Romaria - Prefeitura de Juazeiro do Norte (2016) - http://setur.juazeiro.ce.gov.br/.

Sobre os peregrinos e o ato de peregrinar, este se classifica como uma "experiência individual vivida pelo que faz a jornada". No Estado do Ceará, merece destaque o caminho que o fiel deve percorrer até chegar o Santuário de São Francisco em Canindé. São centenas de peregrinos que percorrem o caminho da capital cearense à Canindé (cerca de $108 \mathrm{~km}$ ) anualmente carregando cruzes, seguindo o percurso descalços, de joelhos ou mais atualmente de bicicletas. Na semana de 26 de setembro a 4 de outubro (dia de São Francisco), cerca de 2,5 milhões de pessoas visitam a cidade; embora haja peregrinos de todas as classes sociais, a imensa maioria é de pessoas humildes (PREFEITURA DE CANINDÉ, 2016).

O autor Terrin (2004), diferencia o turista e o peregrino, explicando que:

Peregrinar é aceitar viver numa condição "liminar"na qual não se está mais integrado numa sociedade, mas se está a caminho para alguma outra coisa, e para isso é preciso fazer sacrifícios, submeter-se a fadigas, aceitar dificuldades. O turista dificilmente pode ser considerado um peregrino. O que impele o turista é a curiosidade, a diversão, à vontade de sair do seu ambiente. O peregrino é 
um buscador, um penitente, um "margilizado social", mesmo que apenas por um certo período... Sabe aceitar os sofrimentos para poder chegar aquele lugar ou àquele não-lugar que constitui para ele o ponto de "saturação do sagrado", capaz de transformá-lo interiormente (TERRIN, 2004, p.374).

Dessa forma percebemos que o Romeiro e o Peregrino mesmo tendo efetivando uma jornada religiosa, seja esta comum ou individual, se diferenciam de um turista que visita um local religioso, pois esse último busca o lazer em primeiro lugar, além de outras motivações semelhantes à dos turistas que visam conhecer atrativos culturais de uma forma geral.

Vale ressaltar que tais definições apresentam controvérsias entre acadêmicos, não se chegando a um consenso se tais sujeitos sociais se enquadrariam ou não como turistas. Entretanto, com vistas a esclarecer o posicionamento dos autores do presente artigo ao leitor, frisa-se que estes se basearam na definição geral do turismo, que classifica como turista a pessoa que se desloca por um tempo superior a 24 horas para outro destino e que não exerça atividade renumerada. Dessa forma, os romeiros e peregrinos também se enquadram, de uma visão ampla, como turistas e nesse caso "turistas religiosos".

\section{TURISMO RELIGIOSO NO CEARÁ}

O Ceará já é destaque no Turismo Nacional. Conforme dados levantados pela Secretária de Turismo do Ceará (SETUR), no primeiro semestre de 2015 o fluxo turístico internacional foi $21 \%$ maior que o mesmo período em 2014. Além de números, a qualidade do destino também foi analisada, através do grau de satisfação dos turistas. Segundo a pesquisa, $62 \%$ desses consideram que o destino superou as expectativas, e 37,2\% responderam que o destino correspondeu ao que esperavam.

No segmento religioso o estado também se sobressai, onde em uma perspectiva nacional, possui um dos três maiores destinos de Turismo Religioso, a cidade de Juazeiro do Norte, localizada na região do Cariri. Segundo dados do Ministério do Turismo, cerca de 2,5 milhões de devotos do Padre Cícero visitam a cidade anualmente. Estima-se que somente na romaria de finados do ano de 2016, receberam mais de meio milhão de pessoas como indicado no tópico 2.1 .

O Cariri é considerado pela SETUR como um pólo religioso, pois a região possui outros destinos que movimentam o segmento, como a cidade de Barbalha, que atrai milhares de fiéis na festa anual de seu padroeiro,
Santo Antônio. Ao chegar no Sertão Central, encontrase outro importante destino para a religiosidade cearense, o município de Canindé, que possui como padroeiro São Francisco das Chagas. A estátua que está localizada próxima à cidade como local de homenagem ao santo, possui proporções um pouco maiores que a do Cristo Redentor, localizada no Rio de Janeiro. Estimase que anualmente, um milhão de pessoas visite a estátua de São Francisco.

Ainda sobre o Ceará, especificamente, pode-se indicar outras festividades religiosas que movimentam o turismo religioso. Dentre elas, ordenaram-se as principais no Quadro 1 abaixo:

Como se pode observar no quadro acima, muitas festividades se repetem, uma vez que o santo de devoção da população por vezes é o mesmo padroeiro, mas em municípios diferentes. Vale ressaltar que para além das festividades, os turistas visitam também as igrejas destes municípios como forma de conhecer a cultura da região. Não obstante à tais municípios, a cidade de Fortaleza também se enquadra nesse cenário. A Festa de Nossa Senhora de Assunção, que ocorre no 15 de agosto e é celebrada pela Arquidiocese de Fortaleza (Catedral) com a Caminhada de Maria. Entretanto, no Centro de Fortaleza, uma série de igrejas se materializam como pontos turísticos frequentados por quem visita a cidade.

\subsection{O Centro de Fortaleza: perspectivas históricas e culturais}

O Centro da cidade de Fortaleza possui diversos edifícios antigos, que foram tombados e preservam sua arquitetura original. Dentre eles, as igrejas se destacam por sua diversidade, principalmente relacionado à sua arquitetura e proporções.

Fortaleza no Período Colonial do Brasil passou muitos anos em esquecimento, sendo apenas uma pequena vila não muito povoada, onde a pouca população que existia se concentrava em torno do Rio Pajeú, onde hoje se trata da região próxima ao Museu do Ceará e a atual Catedral Metropolitana.

Esse cenário se modificou com o fortalecimento da economia do algodão, e também com melhorias no porto de Fortaleza. Segundo Jucá (2007, p.254-255), o Ceará se encontrava todo interligado por estradas por onde circulavam as boiadas, resistentes à seca de 1793 e seus derivados, o algodão que se tornou a principal fonte econômica da Província cearense por toda aquela centúria e todos os demais produtos que abasteciam as vilas.

Através desses fatores, foi possível que Fortaleza se tornasse uma das principais exportadoras de algodão 
Quadro 1: Quadro das Festividades Religiosas principais no Estado do Ceará

\begin{tabular}{|c|c|c|c|}
\hline MÊSS & DIA & SANTO(A) HOMENAGEADO & CIDADE \\
\hline Julho & 06 a 15 & Nossa Senhora do Carmo & Jucás - CE \\
\hline Julho & 14 a 20 & São Benedito & São Benedito - CE \\
\hline Julho & 16 & Nossa Senhora do Carmo & Pacatuba - CE \\
\hline Julho & 16 a 24 & Nossa Senhora Sant'anna & Iguatu - CE \\
\hline Julho & 18 a 27 & Nossa Senhora Santana & Santana do Cariri - CE \\
\hline Julho & 26 & Nossa Senhora Santana & Jaguaruana - CE \\
\hline Agosto & 05 a 15 & Nossa Senhora das Graças & Graça - CE \\
\hline Agosto & 05 a 15 & Nossa Senhora do Perpétuo Socorro & Apuiarés - CE \\
\hline Agosto & 05 a 15 & Nossa Senhora do Perpétuo Socorro & Reriutaba - CE \\
\hline Agosto & 06 a 15 & Nossa Senhora de Palma & Baturité - CE \\
\hline Agosto & 10 a 15 & Nossa Senhora da Saúde & Tabuleiro do Norte - CE \\
\hline Agosto & 15 & Coroação de Nossa Senhora & Aratuba - CE \\
\hline Agosto & 15 & Festa de Iemanjá & Fortaleza - CE \\
\hline Agosto & 15 & Nossa Senhora da Assunção & Fortaleza - CE \\
\hline Agosto & 15 a 22 & Nossa Senhora da Conceição & Hidrolândia - CE \\
\hline Agosto & 29 a $08 / 09$ & Nossa Senhora da Saúde & Fortaleza - CE \\
\hline Agosto & 29 a $08 / 09$ & Nossa Senhora da Auxiliadora & Carnaubal - CE \\
\hline Setembro & 01 a 08 & Nossa Senhora da Saúde & Frecheirinha - CE \\
\hline Setembro & 03 a 15 & Nossa Senhora das Dores & Juazeiro do Norte - CE \\
\hline Setembro & 07 & Nossa Senhora da Paz & Arneiroz - CE \\
\hline Setembro & 17 a 27 & São Cosme e Damião & Pereiro - CE \\
\hline Setembro & 20 a 30 & Nossa Senhora Perpétuo Socorro & Acopiara - CE \\
\hline Setembro & 24 & Nossa Senhora das Mercês & Itapipoca - CE \\
\hline Setembro & 24 a $24 / 10$ & São Francisco & São Benedito - CE \\
\hline Setembro & 26 a $04 / 10$ & São Francisco & Quixadá - CE \\
\hline Setembro & 26 a $04 / 10$ & São Francisco & Cariré - CE \\
\hline Setembro & 26 a $04 / 10$ & São Francisco & Cascavel - CE \\
\hline Outubro & 04 & São Francisco das Chagas & Canindé - CE \\
\hline Outubro & 07 & Nossa Senhora do Rosário & Groaíras - CE \\
\hline Outubro & 22 a 31 & Santa Rita de Cássia & Paraipaba - CE \\
\hline Outubro & 25 a 30 & Nossa Senhora Perpétuo Socorro & Alcântara - CE \\
\hline Novembro & 01 a 02 & Padre Cícero & Juazeiro do Norte - CE \\
\hline Novembro & 01 a 02 & Peregrinação ao Parazinho & Granja - CE \\
\hline Novembro & 06 a 14 & São Gonçalo & São Gonçalo do Amarante - CE \\
\hline Novembro & 26 a $08 / 12$ & Nossa Senhora da Conceição & São Benedito - CE \\
\hline Novembro & 28 a $08 / 12$ & Nossa Senhora da Imaculada Conceição & Meruoca - CE \\
\hline Novembro & 29 a 30 & Nossa Senhora dos Navegantes & Aquiraz - CE \\
\hline Novembro & 30 a $08 / 12$ & Nossa Senhora da Conceição & Pacoti - CE \\
\hline Dezembro & 04 a 13 & Santa Luzia & Baturité - CE \\
\hline Dezembro & 08 & Nossa Senhora da Conceição & Pacatuba - CE \\
\hline Dezembro & 08 & Nossa Senhora da Conceição & Acaraú - CE \\
\hline Dezembro & 22 a $01 / 01$ & São Francisco de Paula & Aratuba - CE \\
\hline Dezembro & 23 a $01 / 01$ & Senhor do Bonfim & Icó - CE \\
\hline Dezembro & 26 a $01 / 01$ & Senhor do Bonfim & Crateús - CE \\
\hline
\end{tabular}

Fonte: http://www.ceara.com.br/cepg/festas.htm 
para a França, país que possuía forte relação econômica com o Brasil. Isso proporcionou um maior desenvolvimento na antiga Vila do Forte, que foi elevada a cidade em 1832.

Lemenhe (1991, p.86) relata que a capital, por volta de 1814, [...] apresentava menor arrecadação sobre produtos exportados do que Aracati, porém em 1835 supera, em muito, esta ultima.

Desde então, importantes prédios e importantes locais da cidade iniciaram sua construção. A Praça dos Mártires, primeira praça pública de Fortaleza, foi local de confraternização da sociedade cearense por muitos anos. A Praça conseguia reunir membros de classes sociais diferentes, mesmo que existisse a divisão do espaço referente a essas classes. Essa praça conseguiu preservar até os dias de hoje um terço de seu tamanho original, sendo o restante tomado pela $10^{\mathrm{a}}$ Região Militar de Fortaleza, que funciona dentro do Forte de Nossa Senhora de Assunção, outro importante prédio que foi essencial na colonização da região cearense.

A Praça do Ferreira, construída no final do século XIX, é hoje uma das praças mais conhecidas e frequentadas, sendo um dos cartões-postais da cidade de Fortaleza. Em seu entorno, conseguiu preservar a maioria dos prédios que foram construídos no início do século XX, prédios esses com inspiração na arquitetura francesa. Vale ressaltar que na Segunda metade do Século XIX, a partir dos anos de 1850, a cidade passou por profundas mudanças em sua infraestrutura e equipamentos urbanos, visando atender novas demandas, disciplinando espaços e controlando a população. "Viveuse uma explosão de modernidades e aformoseamentos (embelezamentos) quando os discursos e as práticas sociais buscavam imitar a civilidade europeia. Fortaleza, então, destacou-se entre as maiores cidades do País" (FARIAS, 2015, p.219).

Essa inspiração se deu em um movimento que surgiu em todo o país relacionado a urbanização. Segundo Castro:

No afã de incorporar o País nos padrões arquitetônicos e urbanos de cunho europeu, desenvolve-se uma campanha permanente em favor do progresso e da civilização, que toma a França como parâmetro superior.(Castro in Fabris. 1987:213).

Em entrevista realizada com o professor José Borzacchielo da Silva, em 2009:

Quando surge o movimento da sociedade que se manifesta no bairro esta imbricação do su- jeito, o lugar adquire outra conotação da dimensão do sujeito, não o lugar com uma natureza ontológica própria. Ele só é lugar porque é condição de realização dos sujeitos sociais. Sob esta ótica, este lugar tem cheiro, movimento; pode ser bairro, setor, cidade. $\mathrm{O}$ centro da cidade é o ponto de convergência, é onde os gritos ecoam e têm repercussão.

Seguindo esse pensamento, percebemos que o centro, como bairro e lugar possui uma grande relevância para a cidade, pois foi nele onde a mesma nasceu, onde iniciou sua história e deixou marcas do passado, se tornando um lugar que se diverge de outros bairros que surgiram posteriormente com o crescimento da cidade.

O Centro de Fortaleza segue então como o local dentro da cidade mais rico em história e cultura na cidade. É objeto de visitação dos turistas e residentes que se interessam em conhecer mais sobre a capital do Ceará. Foi exatamente nesse espaço praticado que se materializaram as entrevistas semiestruturadas com 45 turistas no período de janeiro a fevereiro do corrente ano, período considerado de alta estação, onde a aplicação desse instrumental ocorreu por meio de abordagem direta no Mercado Central de Fortaleza. É referente aos resultados das tabulações de tais questionários que o tópico subsequente se materializa.

\subsection{A Viabilidade de um roteiro religioso para o Centro de Fortaleza: o olhar do turista sobre as igrejas enquanto atrativos turísticos}

Conforme Beni (2001), "todo lugar, objeto ou acontecimento de interesse turístico que motiva o deslocamento de grupos humanos pode ser considerado como atrativo turístico" (p.297). Conforme o autor (op.cit.), os atrativos turísticos podem ser transformados em recursos turísticos, sendo estes, elementos passíveis de provocar deslocamentos de pessoas, e que interagem com o marco geográfico-ecológico-cultural de uma localidade.

Dentre os atrativos turísticos se enquadrariam alguns componentes do patrimônio cultural à exemplo de sítios, ruínas, pinturas, monumentos, instituições culturais de pesquisa, estudo e lazer, gastronomia; artesanato; festas comemorações e igrejas. Nesse contexto, Através da aplicação do questionário semiestruturado, foi possível identificar a visão do turista em relação a aspectos que torna possível a identificação da viabilidade de um roteiro turístico.

De um modo geral, $64 \%$ dos entrevistados eram do sexo feminino. Em relação a localidade de origem, foi 
possível entrevistar ao menos um turista vindo de 16 estados diferentes do país, sendo ao menos um de cada região. Pode-se analisar o grau de instrução dos entrevistados, onde a maioria possui o ensino médio completo $(31,5 \%)$, enquanto $28,5 \%$ possui curso superior, e outros $23 \%$ se encontram cursando nível superior. Apenas $9 \%$ foram representados por aqueles que possuem o ensino fundamental completo, enquanto 8 são pessoas com pós-graduação concluída, seja ela especialização, mestrado ou doutorado. A faixa etária dos entrevistados apresentou resultados bem equilibrados, onde foi proporcional o número de turistas para cada grupo de idade, sendo essas de 18 a 21 anos, de 22 a 30 anos, de 31 a 40 anos, de 41 a 50 anos e acima de 50 anos.

A segunda parte do questionário levantou questionamentos sobre a religião dos entrevistados, o interesse na visitação de locais com a temática religiosa e o interesse que os mesmos possuem em visitar locais de importância histórica e cultural de uma localidade. Foi constatado que $60 \%$ dos turistas se declararam católicos, sendo, apenas, $20 \%$ de evangélicos. O fato da maioria dos sujeitos sociais serem da religião católica indicou um interesse maior por esse público a conhecer atrativos turísticos religiosos como igrejas, mas o fato de outras pessoas de religiões diversas terem respondido as questões, não inviabilizou que fosse constatado o interesse de turistas que não são católicos em conhecerem tais atrativos. Ou seja, 77\% dos turistas possuem interesse em visitar locais de aspectos religiosos, contra $33 \%$ que não possuem. O interesse desse quantitativo que conhecerem atrativos religiosos culturais coaduna com o fato de associarem essas visitas à importância cultural da cidade que estão visitando. Ou seja, 96\% dos turistas informaram que gostam de visitar locais de relevância cultural e histórica.

Durante os diálogos que transcorriam informalmente durante a aplicação do instrumental se observou que a maioria das pessoas conheciam ou tinham ouvido falar em alguma igreja da cidade de Fortaleza, onde, através da tabulação, se concluiu que apenas $20 \%$ dos turistas não conhecem qualquer igreja da capital cearense. A maioria apontou conhecer ou ter ouvido falar sobre a Catedral Metropolitana (97,2\%), enquanto uma minoria assinalou conhecer ou ouvido falar das Igreja do Carmo (11\%), Igreja do Patrocínio (2\%), Santuário Coração de Jesus (11\%), e Igreja Nossa Senhora da Conceição da Prainha (19,5\%). Esse conhecimento prévio, se deu por pesquisas antes de chegarem à Fortaleza ou por informações de amigos que já haviam conhecido a cidade.

Foi ainda questionado aos turistas se os mesmos pensaram, antes de chegar a Fortaleza, na possibilidade de participarem de um roteiro que incluísse as igrejas, como opção do que se conhecer na cidade. $77,8 \%$ dos turistas não pensaram em uma alternativa como essa, ao menos não enquanto materialidade de um roteiro; contra $22 \%$ que afirmam ter pensado em um roteiro como esse.

Apesar do grande número de pessoas que não pensaram em um roteiro religioso como alternativa de turismo em Fortaleza, 65\% afirmou que teriam interesse em um roteiro de duas horas onde o foco seria a visitação de oito igrejas de relevância histórica para o centro da cidade, caso houvesse tal possibilidade.

Dessa forma, percebemos que apesar da imagem de um roteiro religioso não existir quando os mesmos pensam nos atrativos de Fortaleza, percebemos que existe uma demanda que possui um interesse em realizar um city tour voltado para esse segmento, tanto pelo interesse em se aproximar cultura do Ceará, como pelo fato da religiosidade despertar nesses sujeitos o desejo de conhecer os atrativos turísticos religiosos da cidade.

\section{UMA PROPOSTA DE ROTEIRO RELIGIOSO PARA O CENTRO DE FORTALEZA: AS IGREJAS CATÓLICAS EM FOCO.}

Como uma das formas de propagar o Turismo Religioso e Cultural da cidade, uma proposta de roteiro composto por oito igrejas católicas localizadas no centro da capital cearense, e em regiões próximas ao mesmo se torna uma boa opção de city tour. Conforme Brambatti (2002), "os roteiros são percursos, caminhos, rotas percorridas por turistas, com o objetivo de usufruir um contexto, visto no seu conjunto, de forma organizada e atrativa" (p.15).

O roteiro aqui proposto é formado pelas Igreja da Sé (Catedral Metropolitana de Fortaleza), Igreja do Rosário, Igreja Pequeno Grande, Igreja Nossa Senhora da Conceição da Prainha, Igreja São Bernardo, Igreja do Carmo, Igreja do Patrocínio e o Santuário Sagrado Coração de Jesus. Todas essas igrejas apresentam uma relevância, seja religiosa ou histórica, para a cidade de Fortaleza, além de possuírem uma boa estrutura para que sejam visitadas (Quadro2). 
TURISMO RELIGIOSO: UM ESTUDO SOBRE A DEMANDA DE UM ROTEIRO TURÍSTICO DAS IGREJAS CATÓLICAS DO CENTRO DE FORTALEZA - CEARÁ - BRASIL

Quadro 2: Dados Gerais das Igrejas que compõe o roteiro.

\begin{tabular}{|c|c|c|c|c|}
\hline IGREJA & $\begin{array}{c}\text { ANO } \\
\text { DE } \\
\text { INAUGURAÇÃO }\end{array}$ & PADROEIRO & LOCALIZAÇÃO & $\begin{array}{l}\text { INFORMAÇÕES } \\
\text { BÁSICAS }\end{array}$ \\
\hline $\begin{array}{c}\text { Catedral Metropolitana } \\
\text { de Fortaleza }\end{array}$ & 1978 & $\begin{array}{c}\text { Nossa } \\
\text { Senhora de Asssunção }\end{array}$ & $\begin{array}{l}\text { Rua São José, } \\
\text { Praça da Sé, } \\
\text { S/N, Centro. }\end{array}$ & $\begin{array}{l}\text { Com altas torres } \\
\text { representando o } \\
\text { estilo arquitetônico } \\
\text { Neo gótico, a catedral } \\
\text { é uma das maiores do país, } \\
\text { comportando até } 5.000 \text { pessoas }\end{array}$ \\
\hline $\begin{array}{c}\text { Igreja de Nossa Senhora } \\
\text { da Conceição } \\
\text { da Prainha }\end{array}$ & 1841 & $\begin{array}{c}\text { Nossa } \\
\text { Senhora da Conceição }\end{array}$ & $\begin{array}{c}\text { Av. Monsenhor Tabosa, } \\
\text { S/N, } \\
\text { Praia de Iracema }\end{array}$ & $\begin{array}{l}\text { A igreja inspirada em } \\
\text { estilo arquitetônico } \\
\text { neoclassico é anexa } \\
\text { ao Seminário da } \\
\text { Prainha. }\end{array}$ \\
\hline $\begin{array}{c}\text { Igreja do Pequeno } \\
\text { Grande }\end{array}$ & 1903 & - & $\begin{array}{l}\text { Av. Santos Dumont, } \\
55, \\
\text { Centro. }\end{array}$ & $\begin{array}{l}\text { Primeiro edifício } \\
\text { fortalezense construído } \\
\text { com estrutura de ferro. }\end{array}$ \\
\hline $\begin{array}{c}\text { Igreja } \\
\text { do Rosário }\end{array}$ & 1730 & $\begin{array}{c}\text { Nossa } \\
\text { Senhora do Rosário }\end{array}$ & $\begin{array}{c}\text { Rua do Rosário, } \\
229, \\
\text { Centro. }\end{array}$ & $\begin{array}{l}\text { Primeiro templo religioso } \\
\text { de Fortaleza, a pequena } \\
\text { igreja já foi a catedral } \\
\text { por } 40 \text { anos. }\end{array}$ \\
\hline $\begin{array}{c}\text { Santuário Sagrado } \\
\text { Coração de Jesus }\end{array}$ & 1961 & $\begin{array}{c}\text { Sagrado } \\
\text { Coração de Jesus }\end{array}$ & $\begin{array}{c}\text { Av. Duque de Caxias, } \\
135, \\
\text { Centro }\end{array}$ & $\begin{array}{l}\text { Após ser reconstruída, } \\
\text { a igreja foi elevada ao } \\
\text { nível de Santuário. }\end{array}$ \\
\hline $\begin{array}{c}\text { Igreja } \\
\text { do Carmo }\end{array}$ & 1906 & $\begin{array}{c}\text { Nossa } \\
\text { Senhora do Carmo }\end{array}$ & $\begin{array}{l}\text { Av. Duque de Caxias, } \\
\text { S/N, } \\
\text { Centro }\end{array}$ & $\begin{array}{l}\text { A igreja possui uma } \\
\text { grande estrutura para } \\
\text { fieis. }\end{array}$ \\
\hline $\begin{array}{c}\text { Igreja } \\
\text { São Bernardo }\end{array}$ & 1858 & $\begin{array}{c}\text { Nossa } \\
\text { Senhora do Bom Parto }\end{array}$ & $\begin{array}{c}\text { Rua Senador Pompeu, } \\
1206, \\
\text { Centro }\end{array}$ & $\begin{array}{l}\text { Uma pequena igreja } \\
\text { localizada bem no meio } \\
\text { do centro da cidade, } \\
\text { mas se trata de uma das mais } \\
\text { antigas da região. }\end{array}$ \\
\hline $\begin{array}{l}\text { Igreja do } \\
\text { Patrocínio. }\end{array}$ & 1852 & $\begin{array}{c}\text { Nossa Senhora } \\
\text { do Patrocínio }\end{array}$ & $\begin{array}{l}\text { Rua Guilherme Rocha, } \\
536, \\
\text { Centro }\end{array}$ & $\begin{array}{l}\text { Localizada na Praça José } \\
\text { de Alencar, a igreja } \\
\text { recebe um grande número } \\
\text { de pessoas diariamente }\end{array}$ \\
\hline
\end{tabular}

Fonte: Pesquisa Direta, 2017 
A proposta é que o mesmo se inicie pela Catedral, aonde, respectivamente, virão às visitações da Igreja Nossa Senhora da Conceição, Igreja Pequeno Grande, Igreja do Rosário, Santuário Sagrado Coração de Jesus, Igreja do Carmo, Igreja São Bernardo e Igreja do Patrocínio.

O local de partida foi escolhido analisando a proximidade da Catedral com o Mercado Central, pois esse é um local estruturado com estacionamento para ônibus e vans, além de ser um ponto fácil de locomoção, e também de fácil acesso, como pode ser visto no Roteiro proposto abaixo (Figura 2).

Figura 2: Mapa de Roteiro do Centro da Cidade de Fortaleza com pontuações das igrejas

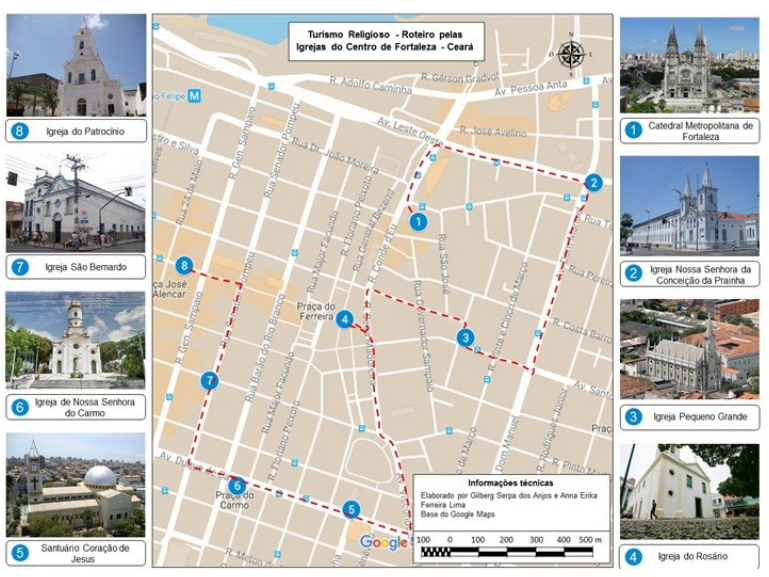

A análise das pesquisas realizadas com os turistas foi outro importante fator que motivou a escolha da Catedral como primeira igreja a ser visitada. Dos turistas que conhecem de alguma forma as igrejas localizadas no Centro de Fortaleza, 97,5\% declaram ou já ter tido a oportunidade de visitar a igreja, ou ter ouvido falar através de conhecidos e internet.

A escolha da ordem das outras igrejas foi feita de acordo com a localização das mesmas na cidade, priorizando um caminho a ser seguido que otimize o tempo e proporcione uma melhor visitação.

Nesse city tour, além do foco nas igrejas, o qual terá duração de três horas de acordo com a demanda levantada durante a pesquisa, o turista terá a oportunidade de visualizar importantes atrativos do centro durante o percurso de locomoção de uma igreja para outra, como a Praça dos Leões que é composta por prédios antigos, incluindo o que funciona o Museu do Ceará, o Centro Cultural Dragão do Mar, a Praça José de Alencar, dentro outros atrativos.
De acordo com Crestani (2012), os roteiros quando bem elaborados conseguem montar a "alma" do lugar. Eles não são apenas uma sequência de atrativos a serem visitados, são também uma ferramenta para a leitura da realidade existente e da situação sociocultural vigente de uma determinada localidade. Quando se elabora um roteiro é preciso que esteja dentro de sua realidade e contendo uma sequência lógica, dando uma visão de uma forma mais completa possível, mostrando o local em todos os seus aspectos. Para sua elaboração, várias habilidades são necessárias, como: a intuição, a criatividade e muita pesquisa.

\section{CONSIDERAÇÕES FINAIS}

Conforme o estudo sobre os tópicos que desenvolveram essa pesquisa, percebemos que o turismo religioso é um segmento que vem crescendo cada vez mais. Através dele podem ser explorados alternativas que influenciem no crescimento do setor turístico no Ceará.

Como destino turístico, Fortaleza possui um grande potencial ainda a ser explorado que possa ser significante para o desenvolvimento da atividade. Com essa pesquisa, verificamos o potencial existente no centro da cidade, ao que se diz a respeito seu patrimônio material composto de igrejas católicas.

A proposta de roteiro aqui deixada é uma oportunidade de ser desenvolvido por empresas de turismo ou órgãos públicos responsáveis pela gestão do turismo como uma alternativa ao que já é feito na cidade, pois foi identificado demanda para esse tipo de city tour. O roteiro poderia ainda, contribuir de forma positiva para a imagem da cidade.

Sugere-se que posteriormente, novos trabalhos aperfeiçoem o que aqui foi descoberto, onde possa ser possível um estudo também sobre as políticas públicas de Fortaleza e como seria possível inserir esse roteiro no contexto turístico da cidade. Ademais, é necessária uma nova interpretação para o turismo religioso, principalmente no aspecto de melhorias dos atrativos turísticos, dos equipamentos e da infraestrutura urbana nas localidades envolvidas com o processo, principalmente ao que tange às igrejas, objeto de estudo da presente pesquisa.

\section{REFERÊNCIAS}

ANDRADE, J. V. de. Turismo fundamentos e dimensões. São Paulo: Ática, 2000.

BENI, M. C. Análise Estrutural do Turismo. 7. ed. São Paulo: Editora SENAC, 2001. 
TURISMO RELIGIOSO: UM ESTUDO SOBRE A DEMANDA DE UM ROTEIRO TURÍSTICO DAS IGREJAS CATÓLICAS DO CENTRO DE FORTALEZA - CEARÁ - BRASIL

BRASIL, M. d. T. Segmentação do Turismo: Marcos Conceituais. Brasília: Ministério do Turismo.

BUSS, M. D.; MACHADO, E.; FURTADO, S. M. A. Entrevista com o professor josé borzacchiello da silva. Geosul, Florianópolis, v. 24, n. 47, p. 199-221, 2009.

CARVALHO, C. L. Ministro do esporte e turismo e ex-presidente da embratur - instituto brasileiro de turismo. In: Jornal do Brasil. 2000.

CRESTANI, V. T. V. Estudo de viabilidade de implantação de um roteiro turístico abrangendo algumas igrejas e o Colégio Nossa Senhora de Sion em Campanha/MG. 5. ed. Gestão em foco: revista on-line, 2012.

DIAS, R. Planejamento do turismo. política e desenvolvimento do turismo no brasil. In: OLIVEIRA, Laís. Espaço Urbano e Turismo Religioso: Avaliação da Política de Reordenamento do Centro da Cidade de Juazeiro da Norte - CE. Fortaleza: UFC, 2008.

FECOMERCIO. O bilionário mercado religioso. Revista Comércio \& Serviços, n. 39, p. 22-29, 2015.

FERREIRA, L.; AGUIAR, L.; PINTO, J. Turismo cultural, itinerários turísticos e impactos nos destinos. Revista de Cultura e Turismo, n. 2, p. 109-126, 2012.

GOUTHIER, J. Fé faz o Brasil se multiplicar. Rio de Janeiro: Jornal do Brasil, 10 de set., 2000. 8 p.

JUCÁ, N. C. Urbanização do Ceará Setecentista, as vilas de N. S. da Expectação do Ico e de Santa Cruz do Aracati. Salvador: UFBA, 2007.

LEMENHE, M. A. As razões de uma cidade: conflito de hegemonias. Fortaleza: Stylus Comunicações, 1991.

MAHAN, J. Como e por que estudamos a religião e a cultura popular. Estudos Teológicos, v. 38, n. 2, p. 190-198, 1998.

MARTINS, J. C. O. Turismo, Cultutra e Identidade. São Paulo: Roca, 2003.

MCKERCHER, B.; CROS, H. du. Cultural tourism: the partnership between tourism and cultural heritage management. THHP, New York, London, Oxford, 2002.
MINISTÉRIO, T. do. Disponível em:

<http://www.turismo.gov.br/ultimas-noticias/ 2133-turismo-religioso-ganha-espaco-no-nordeste. html>

OLIVEIRA, C. D. M. de. Turismo religioso: Uma breve apresentação. In: Jormal O Lince. 2008. Disponível em: <http://www.jornalolince.com.br/2008/fev/agora/ turismoreligioso_jornalolince_edicao14.pdf $>$. Acesso em: 12 de janeiro de 2017.

RAJ, R. The impact of cultural festivals on tourism. In: Tourism Today - The Journal of the College of Tourism and Hotel Management. 2004. p. 66-77.

SETUR. Secretaria de turismo do ceará. Disponível em: <http://www.ceara.gov.br/sala-de-imprensa/noticias/ 13583-fluxo-de-turistas-estrangeiros-e-21-maior-que-em-2014> Acesso em: Janeiro de 2017.

SMITH, M. Issues in cultural tourism studies. Routeledge, London.

SOUSA, A.; PINHEIRO, C. O papel do turismo religioso nos territórios - caso de lamego (portugal). In: Revista Turydes: Turismo y Desarrollo. 2014. Disponível em: <http://www.eumed.net/rev/turydes/17/lamego.html> Acesso em: 10 de janeiro de 2017.

TERRIN, A. N. Antropologia e Horizontes do Sagrado: Cultura e Religiões. São Paulo: Paulus, 2004.

TORRE, O. de. El Turismo, Fenômeno Social. México: Fondo de Cultura Econômica, 1992.

VAQUERO, M. La ciudad histórica como destino turístico. Ariel, Barcelona, 2006. 


\section{APENDICE A - Questionário aplicado aos turista

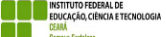 \\ CURSO SUPERIOR DE BACHARELADO EM TURISMO}

Aluno Orientando: Gilberg Serpa dos Anjos

Professora Orientadora: Dra. Anna Érika Ferreira Lima

Trabalho de Conclusão de Curso: Artigo Científico

Este questionário é um instrumento de pesquisa que será aplicado aos turistas do município de Fortaleza, tendo como objetivo analisar o trecho de igrejas pertencentes ao centro, verificando a opinião dos turistas sobre a opinião dos mesmos sobre uma visitação de um trecho em si, caracterizando esse tipo de roteiro como religioso. O presente trabalho está sendo desenvolvido pelo aluno como requisito para obtenção do Grau em Bacharelado em Turismo. Agradecemos desde já pelas informações cedidas.

\section{QUESTIONÁRIO DE PESOUISA PARA TURISTAS}

I- Dados de Identificação

\section{1) Faixa Etária:}

( ) De 18 a 21 anos

( ) De 22 a 30 anos

( ) De 31 a 40 anos

2) Grau de escolaridade:

( ) De 41 a 50 anos ( ) Acima de 51 anos

( ) Ensino Fundamental completo

( ) Ensino Médio completo

( ) Cursando Ensino Superior

( ) Ensino Superior completo

( ) Cursando Pós- graduação

( ) Pós graduação concluída

3) Sexo

( ) Masculino

4) Cidade e Estado onde reside:

II - Fé

1) Você possui alguma religião ligada ao cristianismo?

( ) Sim, sou católico

( ) Sim, sou evangélico

( ) Sim, sou agnóstico

( ) Não sou cristão.

( ) Não sou religioso.

2) Você gosta de visitar locais de importância cultural e histórica?

( ) $\operatorname{Sim}($ ) Não

3) Você gosta de visitar locais de aspectos religiosos, como igrejas e santuários?

( ) $\operatorname{Sim}($ ) Não

4) Assinale as Igrejas de Fortaleza que você já ouviu falar ou conhece.

( ) Igreja da Sé - Catedral Metropolitana

( ) Igreja Nossa Senhora da Conceição da Prainha

( ) Igreja do Patrocínio

( ) Igreja Pequeno Grande

( ) Igreja do Carmo

( ) Santuário Sagrado Coração de Jesus

( ) Igreja de São Bernardo

5) Em caso afirmativo, como conheceu?

( ) Tive a oportunidade de conhecer;

( ) Já ouvi falar por amigos/familiares/conhecidos;

( ) Soube através da internet;

( ) Outros. Especifique:

6) Antes de vir a Fortaleza, você pensou em um roteiro que incluísse as igrejas como alternativa em o que fazer nessa cidade?

( ) Sim ( ) Não

7) Você gostaria de um passeio com duração de duas horas onde o foco seria a visitação de oito igrejas de importância histórica da cidade de Fortaleza?

( ) Sim ( ) Não 